\title{
CAROTID BODY FUNCTION AND VENTILATORY RESPONSES IN INTERMITTENT HYPOXIA. EVIDENCE FOR ANOMALOUS BRAINSTEM INTEGRATION OF ARTERIAL CHEMORECEPTOR INPUT
}

${ }^{1}$ Gonzalez-Martín M.C*., ${ }^{1}$ Vega-Agapito, M.V*., ${ }^{2}$ Conde, S.V., ${ }^{1}$ Castañeda, J. ${ }^{1}$ Bustamante, R., Olea ${ }^{1}$, E., ${ }^{3}$ Perez-Vizcaino, F., ${ }^{1}$ Gonzalez, C. and ${ }^{1}$ Obeso, A.

${ }^{1}$ Departamento de Bioquímica y Biología Molecular y Fisiología e Instituto de Biología y Genética Molecular. Facultad de Medicina. Universidad de Valladolid/CSIC. Valladolid, Spain. ${ }^{2}$ CEDOC Departamento de Farmacología, Facudade de Ciencias Meedicas, Universidade Nova de Lisboa, Portugal. ${ }^{3}$ Departamento de Farmacología. Facultad de Medicina. Universidad Complutense de Madrid. ${ }^{1,3}$ CIBER de Enfermedades Respiratorias.

Running title: Intermittent hypoxia and carotid body function

Correspondence:

Prof. Constancio Gonzalez

Departamento de Bioquímica y

Biología Molecular y Fisiología

Facultad de Medicina.

Universidad de Valladolid

47005 Valladolid. Spain

Phone: +34 983423089

Fax: +34983423588

Email: constanc@ibgm.uva.es

*Both authors have contributed equally to present work. 


\section{ABSTRACT}

Obstructive sleep apnea is a frequent medical condition consisting in repetitive sleep-related episodes of upper airways obstruction and concurrent events of arterial blood hypoxia. To this condition there is a frequent association of cardiovascular and other pathologies conforming the obstructive sleep apnea syndrome (OSAS). Laboratory models of OSAS consist in animals exposed repetitive episodes of Intermittent hypoxia $(\mathrm{IH})$ which also develop cardiovascular pathology, mostly hypertension. The overall OSAS pathophysiology appears to be linked to the repetitive hypoxia, being proposed that it causes a sensitization of carotid body (CB) chemoreflex leading to a hyperreactivity of the sympathetic nervous system. However, this proposal is uncertain because normo or hypoventilation and normal plasma catecholamines are not infrequent findings in patients with OSAS and $\mathrm{IH}$ animals. Aiming to solve these issues we have studied in a rat model of $\mathrm{IH}$ the entire $\mathrm{CB}$ chemoreflex arch including activity of chemoreceptor cells and CB generated afferent activity to brainstem; efferent activity was measured as ventilation in normoxia, hypoxia and hypercapnia. Norepinephrine turnover in renal artery sympathetic endings was also assessed. Findings indicate a sensitization of the CB function to hypoxia evidenced by exaggerated chemoreceptor cell and CB afferent activity. At the same time $\mathrm{IH}$ rats exhibited marked hypoventilation in all studied conditions and increased turnover of norepinephrine in sympathetic endings. We conclude that $\mathrm{IH}$ causes a bias in the integration of the input arising from the $\mathrm{CB}$ with a diminished drive of ventilation and an exaggerated activation of brainstem sympathetic neurons. 


\section{INTRODUCTION}

The carotid bodies (CBs) are small arterial chemoreceptor organs formed by clusters of cells surrounded by a dense net of capillaries that facilitates the presentation of the blood-borne stimuli to chemoreceptor cells. Chemoreceptor cells are synaptically connected with the sensory nerve endings of the carotid sinus nerve (CSN), whose central projections terminate in the brainstem (Gonzalez et al., 1994). Current models of CB functioning consider that chemoreceptor express $\mathrm{O}_{2}$-sensor(s) which are coupled to certain $\mathrm{K}^{+}$channels in such a manner that a decrease in $\mathrm{PO}_{2}$ leads to inhibition of $\mathrm{K}^{+}$channels, cell depolarization, activation of voltage dependent $\mathrm{Ca}^{2+}$ channels and augmentation of the release of neurotransmitters that drive the chemoreceptor cell-nerve ending synapses increasing the action potential frequency in the CSN (see Gonzalez et al., 1992; Peers, 1997; Kemp, 2005; Gonzalez et al., 2009). The end result of hypoxic (low $\mathrm{PO}_{2}$ ) stimulation is the triggering of cardio respiratory reflexes, most significantly hyperventilation, aimed to normalize arterial blood gases, giving a critical homeostatic significance to CB function (Gonzalez et al., 1994). It should be mentioned that CBs are responsible for the entire ventilatory responses produced by hypoxic hypoxia, the only type of hypoxia occurring physiologically as in journeying or living at high altitude (Forster et al., 1976).

The CBs and CB-initiated reflexes play an adaptive function in response to chronic sustained hypoxia (Weil, 1986; Bisgard 2000). On ascension to high altitude the CBs trigger a ventilatory response whose relationship to arterial $\mathrm{PO}_{2}$ is comparable to that encountered at sea level in response to acute hypoxic tests. However, if stay at high altitude is prolonged, a further increase in ventilation occurs. This extra gain of the chemoreflex, known as acclimatization, helps to minimize the impact of the environmental challenge by raising arterial $\mathrm{PO}_{2}$ and might constitute a compensatory mechanism in situations of hypoxemia produced by chronic respiratory diseases. Most of the extra gain of the CB chemoreflex seen in chronic hypoxia has its origin in the CB itself, although plastic changes in brain-stem integrative centers have also been described (Bisgard, 2000; Wilkinson et al., 2010). 
Another type of chronic hypoxia that has a great clinical significance is the intermittent hypoxia $(\mathrm{IH})$ encountered in patients with obstructive sleep apnea (OSA). These patients suffer repetitive episodes of obstruction of upper airways that occur during sleep (>30 episodes/sleep hour in some patients). Each obstruction produces a fall in arterial $\mathrm{PO}_{2}$ that activates the $\mathrm{CB}$ generating a progressively increasing drive to brainstem respiratory nuclei that finally solves the obstruction and blood gases return to normality. Frequently, patients suffering OSA show a number of associated pathologies, mostly cardiovascular (hypertension, augmented acute vascular events) and neuropsychiatric (anxiety, depression and cognitive impairment) (Sateia, 2003; Schröder and O'Hara, 2005), conforming what is known as obstructive sleep apnea syndrome (OSAS). It has been proposed that the CB chemoreflex plays a key pathogenic mechanism in the cardiovascular pathology in OSAS: repeated stimulation during the apneic episodes would cause a sensitization of the CB chemoreflex that would ultimately produce a sustained sympathetic drive and increase in circulating catecholamine (CA; Bao et al., 1997; Kumar et al., 2006).

Although this pathogenic schema has been proposed on the basis of studies in animal models of $\mathrm{IH}$, there are several aspects of it that remain unsettled. For example, the ventilatory response to acute hypoxic tests that measures the gain of the CB chemoreflex has yielded conflicting-results, both in OSAS patients and in IH animal models (Costes et al., 1995; Kimoff et al., 1997; Osanai et al., 1999; Greenberg et al., 1999; Ling et al., 2001; Peng et al., 2006; Zoccal et al., 2008). Similarly, measurements of adrenal medulla CA have yielded opposite results in the two available studies (Hui et al., 2003; Kumar et al., 2006), and measurements of circulating CA have yielded inconclusive results (Fletcher et al., 1992; Lesske et al., 1997; Garcia-Rio et al., 2000). In the present work we have studied the entire chemoreflex arch in rats subjected to $\mathrm{IH}$. Specifically we have measured levels of catecholamines (CA) in CB chemoreceptor cells and their rate of synthesis and release with findings indicating a sensitization of chemoreceptor cells to hypoxia. We have measured electrical activity in the CSN to directly assess the final CB output to the brainstem with findings similarly indicating a hypoxic sensitization of the overall arterial chemoreception process. However, ventilatory response to hypoxia was significantly attenuated indicating that $\mathrm{IH}$ causes central plastic reorganization 
of $C B$ chemoreceptor input leading to a hyposensitivity of the ventilatory and to a facilitation of the vasopressor component of the chemoreflex arch.

\section{MATERIAL AND METHODS}

Animals and anesthesia. In this study we used adult Wistar male rats of $300-380 \mathrm{~g}$ of body weight. When required animals were anaesthetized with sodium pentobarbital (60 mg/kg, i.p.) dissolved in physiological saline. Animals were euthanized by an intracardiac overdose of Na-pentobarbital. Institutional Committee of the University of Valladolid for Animal Care and Use approved the protocols.

Exposure to intermittent hypoxia. Four rats were housed in hermetically shielding transparent methacrylate chambers (16 I), along with food and water. Each chamber has a gas inlet in front; inside the chamber, $3 \mathrm{~cm}$ separated from the front wall, there is an incomplete wall that breaks the gas jet smoothing and slowing the flow of gas in the rats room. Two outlets for the exit of gas of the chamber are located at the back of the chamber; in one of them there is an $\mathrm{O}_{2}$ meter to continuously monitor the gas leaving of the chamber. Gases flow into the chamber from tanks connected in cascade with stainless steel tubing and intercalated manometers to assure several days of supply. Flow of gases into the chamber is controlled by microprocessor driven electrovalves allowing predetermination of time and duration of entry of the desired gas. The electrovalve system is provided with a safety device for unwanted failure of the electrical power. In preliminary experiments the parameters of flow of gases were adjusted to achieve at the outlet of the chambers the desired gas mixture. Animals were exposed to $\mathrm{IH}$ for 8 and 15 days, from 8:00 to 16:00. The intermittent hypoxia pattern was: $10 \% \mathrm{O}_{2}$ for $40 \mathrm{~s}$ and $20 \% \mathrm{O}_{2}$ for 80 s (i.e., 30 episodes/h) .

Surgical procedures. The experiments were performed in the morning at around 9 a.m., i.e., around $16 \mathrm{~h}$ after the completion of their last $\mathrm{IH}$ episode. Animals were tracheostomized and, after adequate dissections, bilateral blocks of tissue containing the carotid bifurcations were removed and placed in a lucite dissecting chamber filled with ice cold $\mathrm{O}_{2}$-saturated Tyrode solution (in $\mathrm{mM}$ : $\mathrm{NaCl}, 140 ; \mathrm{KCl}, 5 ; \mathrm{CaCl}$, 2; MgCl2, 1.1; HEPES, 10; glucose, 5.5; $\mathrm{pH}$ = 7.40). 
For the neurochemical experiments (measurement of content, synthesis and release of $\mathrm{CA}$ ), the CBs were identified and cleaned of surrounding tissues and freed of the CSN with the aid of a dissecting microscope. Cleaned CB, were collected and saved differently according to experimental requirements. For CSN recording, the preparation CB-CSN was identified under a dissecting microscope in situ and a block of tissue, including the carotid bifurcation and the glossopharyngeal nerve, was removed and placed in the dissecting chamber for further cleaning of tissue surrounding $\mathrm{CB}$ and CSN. The preparation CB-CSN was digested during 3-5 $\mathrm{min}$ in collagenase type I $(1 \mathrm{mg} / \mathrm{ml})$ solution to loosen the perineurium. Thereafter the CB-CSN preparation was transferred to the recording chamber. In some animals, renal arteries (RA) from their emergence from the aorta to their arrival to the kidney hilium were also removed and dissected free of surrounding connective tissue in the chilled saline.

Basic haematology. Blood was obtained by direct cardiac puncture after an ample thoracotomy. Complete EDTA-blood was used for cellular blood counting in an Advia ${ }^{\circledR}$ Flow Cytometer (Bayer AG; Leverkusen, Germany).

Neurochemical experiments. Measurement of endogenous CA content in the $C B$ and $R A$. For the analysis of endogenous unlabelled $C A$ in the tissues, upon dissection $\mathrm{CB}$ and RA were placed individually in eppendorf tubes containing, respectively, 50 and $100 \mu$ of ice-cold 0.3N PCA. After weighing the tissues free of adherent PCA in an electrobalance (Supermicro, Sartorius), tissues were glass to glass homogenized, centrifuged and aliquots (10-50 $\mu$ l) of supernatants were directly injected into an HPLC system. The HPLC system was composed of a Milton Roy CM 400 pump, a Waters C18 (particle size 4 $\mu \mathrm{m})$ column, a Waters U6K injector, a Bioanalytical Systems LC-4A electrochemical detector (set at a holding potential of $0.75 \mathrm{mV}$ and a sensitivity of 1 to $5 \mathrm{nA}$ ). Mobile phase was, (in $\mathrm{mM}$ ), $\mathrm{Na}_{2} \mathrm{HPO}_{4}, 25$, sodium octane sulphonate, 0.6 and EDTA, 0.1, with $6 \% \mathrm{MET}-\mathrm{OH}, \mathrm{pH}$ adjusted to 3.2 with concentrated phosphoric acid. Identification and quantification of catecholamine was done against external standards and using Peak Sample Data Chromatography System software (Buck Scientific, East Norwalk, CT).

Measurement of the rate of CA synthesis in the CB and RA. General procedures for the synthesis experiments have been described in previous 
publications (Fidone and Gonzalez, 1982; Vicario et al., 2000). In brief, CB and RA were incubated during $2 \mathrm{~h}$ in a Tyrode solution containing tyrosine $(30 \mu \mathrm{M})$, the natural precursor of $\mathrm{CA}$, labelled with tritium $\left(3,5-{ }^{3} \mathrm{H}\right.$-tyrosine, $6 \mathrm{Ci} / \mathrm{mmol}$; Amersham); incubating solution also contained $100 \mu \mathrm{M}$ 6-methyltetrahydropterine and $1 \mathrm{mM}$ ascorbic acid, cofactors for tyrosine hydroxylase and dopamine- $\beta$-hydroxylase, respectively (Fidone and Gonzalez, 1982).. Completed the labelling period, tissues were washed in ice-cold precursor-free Tyrode (5 $\mathrm{min}$ ), homogenized and processed for HPLC as before. Identification and ${ }^{3} \mathrm{H}-\mathrm{CA}$ and labelled precursor in tissue samples were done against external standards and quantification was made by collection of the HPLC column effluents correspondent to the peaks of interest and scintillation counting of the collected effluents.

Measurement of ${ }^{3} \mathrm{H}-\mathrm{CA}$ release by the $\mathrm{CB}$. The measurement of ${ }^{3} \mathrm{H}-\mathrm{CA}$ release by the CB was performed in organs whose CA deposits have previously been labelled by their incubation as in the synthesis experiments but with high specific activity precursor (3,5- ${ }^{3} \mathrm{H}$-tyrosine, $40-50 \mathrm{Ci} / \mathrm{mmol}$; Amersham). Following the labelling of ${ }^{3} \mathrm{H}-\mathrm{CA}$ stores individual $\mathrm{CB}$ were transferred to a scintillation glass vial containing $4 \mathrm{ml}$ of precursor-free Tyrode bicarbonate solution (composition as above except for the substitution of $24 \mathrm{mM} \mathrm{NaCl}$ by 24 $\mathrm{mM} \mathrm{NaHCO}$ ). Vials were kept in a shaker bath at $37{ }^{\circ} \mathrm{C}$ for the entire experiment. Solutions were continuously bubbled with $20 \% \quad \mathrm{O}_{2} / 5 \% \quad \mathrm{CO}_{2}$, balance $\mathrm{N}_{2}$ saturated with water vapour $\left(\mathrm{PO}_{2} \approx 136-140 \mathrm{mmHg}\right)$, except during hypoxic stimulation and high $\mathrm{K}^{+}$stimulation (see below). During the first hour, the incubating solutions were renewed every $20 \mathrm{~min}$ and discarded. Thereafter, solutions were collected every 10 min for analysis of ${ }^{3} \mathrm{H}-\mathrm{CA}$ content. Hypoxic and depolarizing stimuli consisted of $10 \mathrm{~min}$ incubations with low $\mathrm{PO}_{2}$ equilibrated $\left(7 \% \mathrm{O}_{2} ; \mathrm{PO}_{2} \approx 46 \mathrm{mmHg}\right)$ and high $\mathrm{K}^{+}$-containing solutions (35 mM; equiosmolar $\mathrm{Na}^{+}$was removed). Collected solutions were acidified with glacial acetic acid to $\mathrm{pH}=3$ and maintained at $4^{\circ} \mathrm{C}$ to prevent degradation of the ${ }^{3} \mathrm{H}-\mathrm{CA}$ until analysis. The analysis included: adsorption to alumina $(100 \mathrm{mg})$ at $\mathrm{pH}=$ 8.6, washing of alumina with distilled water, bulk elution of all ${ }^{3} \mathrm{H}$-catechols (1 $\mathrm{ml}, 1 \mathrm{~N} \mathrm{HCl}$ ) and scintillation counting. Raising of $\mathrm{pH}$ in the collected solutions from 3 to 8.6 was made by the addition to the vials under continuous shaking 
$3.6 \mathrm{ml}$ of $2 \mathrm{M}$ TRIS-buffer at a $\mathrm{pH}$ of 8.7. CBs from release experiments were analysed as in the synthesis experiments.

Recording of the CSN activity. The CB-CSN preparation was transferred to a recording chamber mounted on a dissection microscope (Nikon) and superfused $\left(37^{\circ} \mathrm{C}\right.$ ) with bicarbonate buffered saline (in $\mathrm{mM}$ : $\mathrm{NaCl} 120$; $\mathrm{NaHCO}_{3} 24 ; \mathrm{KCl} 3 ; \mathrm{CaCl}_{2} 2 ; \mathrm{MgCl}_{2}$ 1.1; glucose 5; $\mathrm{pH}$ 7.40). Recordings of single or few fibers of CSN were made using a suction electrode. The pipette potential was amplified (Neurolog Digimiter, Hertfordshire, England), displayed on an oscilloscope and stored in a PC computer $(200 \mathrm{~Hz}$ acquisition rate, Axonscope, Axon Instruments, USA). Chemoreceptor activity was identified (spontaneous generation of action potentials at irregular intervals) and confirmed by its increase in response to hypoxic superfusion (normoxia: solution equilibrated with $20 \% \mathrm{O}_{2}+5 \% \mathrm{CO}_{2}$, balanced $\mathrm{N}_{2}$; hypoxia: solution equilibrated with $0 \%$ or $5 \% \mathrm{O}_{2}+5 \% \mathrm{CO}_{2}$, balanced N2). CSN activity was digitalized, summed every second and converted into a voltage proportional to the sum. Hypercapnic stimulation consisted in the perfusion of the preparations with solutions equilibrated with $20 \% \mathrm{O}_{2}+20 \% \mathrm{CO}_{2}$, balance $\mathrm{N}_{2}$.

Whole body plethysmography. Ventilation was measured in conscious freely-moving rats by whole body plethysmography. The system (Emka Technolgies, Paris, France) consists of 5 liters metacrylate chambers continuously fluxed (2 l/min). Temperature was maintained in the chamber within the thermo-neutral range $\left(22-24^{\circ} \mathrm{C}\right)$. Tidal volume $(\mathrm{TV} ; \mathrm{ml} / \mathrm{Kg})$ respiratory frequency (Bf; breaths/min) and minute ventilation $(\mathrm{MV} ; \mathrm{ml} / \mathrm{min} / \mathrm{Kg}$ ) were measured. Briefly, the rats were placed in the plethysmographic chamber and breathed room air (control groups) for at least 30 min until adapted to the chamber ambient and they acquired a standard resting behaviour. Thereafter we started recording ventilatory parameters during $20 \mathrm{~min}$, followed by fluxing the chamber with a gas mixture containing 12,10 or $7 \% \mathrm{O}_{2}$ (rest $\mathrm{N}_{2} ; 2 \mathrm{l} / \mathrm{min}$ ) and $5 \% \mathrm{CO}_{2}$ in air. Each hypoxic o hypercapnic exposure was followed by a 20 min in air. The pressure changes within the chamber reflecting tidal volume (TV) were measured with a high-gain differential pressure transducer. Ideally the frequency of pressure fluctuations is identical to breathing movements; spurious fluctuations of the pressure due to animal movements were electronically rejected. The amplitude of the pressure oscillations is proportionally related to 
TV; a calibration of the system by injections of 2 to $5 \mathrm{ml}$ air into the chamber allowed a direct estimation of TV. Pressure signals were fed to a computer for visualization and storage for later analysis with EMKA software.

Presentation of data and Statistics. Data are presented as means \pm SEM. Statistical significance of differences was assessed using a two tailed Student-t-test for unpaired data and for comparisons of more than two groups we have used a two way ANOVA followed by Bonferroni multicomparison test.

\section{RESULTS}

Animals. The protocol of $\mathrm{IH}$ applied in this study did not alter the gain in body weight, which was nearly identical to that observed in controls. Basic haematology, including red cell count, haematocrit, haemoglobin content and other red cell related indexes were not different from control animals. White cell count was also not different from controls, but platelet count that in control rats was $970 \pm 50\left(\times 10^{3} / \mu \mathrm{L}\right)$ was very significantly reduced to $630 \pm 17$ and $602 \pm$ $12\left(\times 10^{3} / \mu \mathrm{L} ; \mathrm{p}<0.001\right.$ in both cases) at 8 and 15 days of $\mathrm{IH}$.

Carotid body CA content. Figure 1 shows the levels of endogenous CA in the CBs of control and 8 and 15 days $\mathrm{IH}$ animals. At 8 days the levels of both $\mathrm{CA}, \mathrm{NE}$ and DA, although showed a tendency to decrease were nearly normal. However at 15 days there were very significant decreases in both NE and DA content that from control levels of $112.3 \pm 12.26$ pmole/mg tissue $(n=24)$ for NE and $314.4 \pm 29.87 \mathrm{pmole} / \mathrm{mg}$ tissue $(\mathrm{n}=24)$ for DA dropped, respectively to $36.2 \pm 2.29$ and $65.4 \pm 5.50$ pmole $/ \mathrm{mg}$ tissue ( $n=9, p<0.01$ in both cases).

Carotid body and renal artery CA synthesis. The rates of CA synthesis from their natural precursor ${ }^{3} \mathrm{H}$-tyrosine by the $\mathrm{CBs}$ of control and 8 and 15 days $\mathrm{IH}$ animals are shown in Figure 2. Measured NE and DA synthesis rates in control CBs were, respectively, $1.6 \pm 0.14$ and $52.0 \pm 3.78$ pmole $/ \mathrm{mg}$ tissue/2h $(n=24)$. The CBs obtained from animals exposed for 8 days to $\mathrm{IH}$ exhibited comparable rates of CA synthesis, but those obtained from 15 days $\mathrm{IH}$ animals exhibited a decreased rate of synthesis to levels $0.8 \pm 0.2$ pmole $/ \mathrm{mg}$ tissue/2h for NE $(n=9 ; p<0.05)$ and to $19.1 \pm 2.10 \mathrm{pmole} / \mathrm{mg}$ tissue/2h for DA ( $=9 ; p<0.01)$. Turnover times, i.e., the ratios of $C A$ content to rate of synthesis 
encountered in control CBs in present experiments were 141 and 12 hours for $\mathrm{NE}$ and DA, respectively. At 8 days of $\mathrm{IH}$ turnover times were quite similar and at 15 days, while NE turnover time remained nearly identical (144h) that for DA decreased by nearly $50 \%$ to $6.88 \mathrm{~h}$, indicating that while NE stores are reduced proportionally to the decreased rate of synthesis, in the case of DA its endogenous storage is reduced in a greater proportion than the rate of synthesis. The different behaviour of both $\mathrm{CA}$ is due to the fact that most of NE in the CB is in sympathetic endings and not in chemoreceptor cells where DA is stored (see Discussion).

The marked effects of $\mathrm{IH}$ on the CA content and rate of synthesis in the CB prompted a comparison with the NE content and rate of synthesis in the sympathetic fibers/endings of the RA. As shown in Figure 3 the content of NE per mg of renal artery in control rats was $5.7 \pm 0.45$ pmole $(n=16)$ and it increased at 8 and 15 days of $\mathrm{IH}$ exposure when it reached levels of $9.6 \pm 1.20$ pmole/mg renal artery tissue $(n=9 ; p<0.01)$. The rate of ${ }^{3} \mathrm{H}-\mathrm{NE}$ synthesis in control renal arteries was $0.16 \pm 0.01$ pmole/mg tissue/2h $(n=16)$ in control rats and increased to $0.3 \pm 0.01 \mathrm{pmole} / \mathrm{mg}$ tissue/2h in rats exposed to $\mathrm{IH}$ during 15 days $(n=10 ; p<0.001)$. These data on renal artery contrast with findings in the $\mathrm{CB}$. Thus, the renal CA storage capacity and rate of synthesis was increased by $\mathrm{IH}$, and turnover time remained nearly constant 71 hour in control animals and $64 \mathrm{~h}$ in 15 days $\mathrm{IH}$ hypoxic animals.

Release of CA in the carotid body. Figures $4 A$ and $B$ show the general protocol and mean time course of the ${ }^{3} \mathrm{H}-\mathrm{CA}$ release experiments in $\mathrm{CB}$ of control and 15 days $\mathrm{IH}$ animals. CA release during normoxic periods was not significantly different between these two groups. In both cases it should be noted the slow decay of the released radioactivity with duration of the

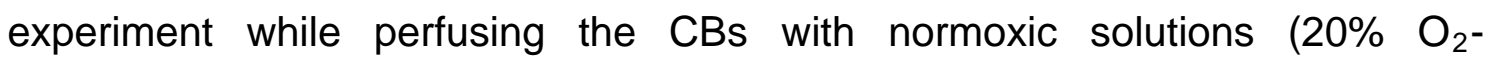
equilibrated, basal release; dashed line across bars); note also that normoxic incubating solutions in the periods following stimulation (10 min superfusion with $7 \% \mathrm{O}_{2}$-equilibrated solution and with a normoxic solution containing $35 \mathrm{mM} \mathrm{K}^{+}$) contained higher amounts of radioactivity due to the slow washing of ${ }^{3} \mathrm{H}-\mathrm{CA}$ and their labelled catabolites released during the stimulation; finally, note the different scale in the $Y$ axis in control and 15 days $\mathrm{IH}$. Computed stimulus- 
induced release (dpm above the dashed lines in Figures $4 A$ and $B$ ) shows that in response to hypoxia $\mathrm{CBs}$ of 8 days $\mathrm{IH}$ animals released ${ }^{3} \mathrm{H}-\mathrm{CA}$ as control CBs, while $\mathrm{CBs}$ from 15 days $\mathrm{IH}$ animals released more than double control amount $(1,274 \pm 383$ vs. $3,565 \pm 624 \mathrm{dpm} / \mathrm{CB} ; \mathrm{n}=16$; $\mathrm{p}<0.001$; Figure $4 \mathrm{C})$. However in response to the non-specific depolarizing high external $\mathrm{K}^{+}$control and 8 and 15 days IH CBS released comparable amounts of ${ }^{3} \mathrm{H}-\mathrm{CA}$ (Figure 4D).

Electrical activity in the carotid sinus nerve. The effects of $\mathrm{IH}$ on the electrical activity of the CSN were assessed on preparations isolated from control and 15 days exposed animals. Basal frequency measured in singlepaucifiber preparations was near to $5 \mathrm{~Hz}(4.9 \pm 0.91 \mathrm{~Hz}$ in control preparations being less than half $(2.2 \pm 0.15 \mathrm{~Hz}$; $(p<0.01)$ in 15 days $\mathrm{IH}$ animals (Figure $5 \mathrm{~B})$. Figure $5 \mathrm{C}$ shows mean responses to moderately intense $\left(5 \% \mathrm{O}_{2}\right.$-equilibrated solutions) and intense ( $\mathrm{N}_{2}$-equilibrated solutions) hypoxia and to hypercapnia (20\% $\mathrm{CO}_{2}$-equilibrated solutions) expressed as times basal normoxic activity. Data indicate that the CBs from $\mathrm{IH}$ animals generated much stronger acute hypoxic responses than controls, so that even if basal activity was significantly lower absolute peak activity was nearly double in $\mathrm{IH}$ animals $(4.9 \mathrm{~Hz} \times 5.63=$ $27.7 \mathrm{~Hz}$ vs. $2.2 \mathrm{~Hz} \times 29.0=63.8 \mathrm{~Hz}$ for $5 \% \mathrm{O}_{2}$, see sample recording in Figure $5 \mathrm{~A}$, and $4.9 \mathrm{~Hz} \times 8.7=42.63 \mathrm{~Hz}$ vs. $2.2 \times 37.9=83.4 \mathrm{~Hz}$ for $\mathrm{N}_{2}$ ). However, the response to $\mathrm{CO}_{2}$ (times basal) was only slightly higher in $\mathrm{IH}$ animals than in controls, making then the absolute hypercapnic peak frequency somehow smaller in IH than in control CBs. The pattern of the CSN response to hypoxia was also different. Thus, while in control preparations the response reached a peak promptly (40 to $60 \mathrm{~s}$ ) and exhibited a certain level of adaptation, which is a common finding in the in control in vitro preparations (Fidone et al., 1982; Conde et al., 2007), in the CB-CSN preparations of $\mathrm{IH}$ animals the activity increased with nearly identical slope for longer period of time to reach the peak activity at 90-120s (Figure $5 \mathrm{D}$ ) and with peak activity higher than in controls (see also Figure 5A). The latency of the hypoxic responses (not shown), which includes the renewal of the solutions in the dead space of the superfusion system, oscillated between 20 and $25 \mathrm{~s}$ and there were not differences between control and IH animals. The response to hypercapnia was, as expected, faster, i.e., latencies (11-14 s, not shown) and time to peaks (26-33 s; Figure 5D) were 
smaller than for the hypoxic stimuli (Fidone and Gonzalez, 1986) and there were not differences between control and $\mathrm{IH}$ animals.

Ventilation. Ventilation was studied in control and 8 and 15 days $\mathrm{IH}$ exposed animals. Figures $6 \mathrm{~A}-\mathrm{C}$ show our main findings along with the protocol of the plethysmography. Breathing frequency (Bf; Figure 6A) in control animals breathing normal air atmosphere ranged between 77 and 88 breaths/min all along the experiments. Changing breathing atmosphere to 12,10 and $7 \% \mathrm{O}_{2}$ significantly increased $\mathrm{Bf}$ to maximum of $151 \pm 6$ breaths/min in $10 \% \mathrm{O}_{2}$; similarly breathing in a $5 \% \mathrm{CO}_{2}$ containing air mixture increased $\mathrm{Bf}$ to $118 \pm 3$ breaths/min. In $\mathrm{IH}$ animals $\mathrm{Bf}$ did not show consistent variations at 8 days of exposure in any of the atmospheres studied but at 15 days of exposure it tended to be lower in all atmospheres, lowering being significant in $10 \% \mathrm{O}_{2}$ to $131 \pm 5$ breaths/min; $(p<0.05)$. Tidal volume/Kg body weight (TV; Figure 6B) in control animals breathing normal air atmosphere in the different moments of the experiment ranged between 5.4 and $6.2 \mathrm{ml} / \mathrm{Kg}$. The 12 and $10 \% \mathrm{O}_{2}$ challenges caused modest increases in TV, but the most intense hypoxic atmosphere (7\% $\mathrm{O}_{2}$ ) very significantly increased TV to $8.8 \pm 0.4 \mathrm{ml} / \mathrm{Kg} ; 5 \% \mathrm{CO}_{2}$ also augmented significantly TV to $7.7 \pm 0.3 \mathrm{l} / \mathrm{Kg}$. Exposure to $\mathrm{IH}$ for 8 days caused minor and variable modifications in TV that did not reach statistical significance in any condition, while after 15 days exposure in all conditions TV were smaller, being the decrease statistically significant at all atmospheres. Minute volume/Kg body weight (MV; Figure 6C) in control animals breathing normal air atmosphere in the different moments of the experiment ranged between 404 and 526 $\mathrm{ml} / \mathrm{Kg} / \mathrm{min}$. Hypoxia produced and increase in MV directly related to its intensity and reached levels of $781 \pm 35 \mathrm{ml} / \mathrm{Kg} / \mathrm{min}$ in the $12 \% \mathrm{O}_{2}$ atmosphere, $898 \pm 46$ $\mathrm{ml} / \mathrm{Kg} / \mathrm{min}$ in the $10 \% \mathrm{O}_{2}$ atmosphere and $1048 \pm 42 \mathrm{ml} / \mathrm{Kg} / \mathrm{min}$ in the $7 \% \mathrm{O}_{2}$ atmosphere; similarly breathing in air containing $5 \% \mathrm{CO}_{2}$ caused $\mathrm{MV}$ to increase to $892 \pm 44 \mathrm{ml} / \mathrm{Kg} / \mathrm{min}$. Exposure to $\mathrm{IH}$ for 8 days caused a tendency for no change in MV to increase at any given experimental time in normoxia, and in the normoxic period after breathing $10 \% \mathrm{O}_{2}$ the increase reached statistical significance ( $43 \%$ increase; $p<0.01$ ); no differences were observed in hypoxic and hypercapnic atmospheres. Contrary to that, after 15 days exposure in all conditions MV were smaller than in unexposed animals except while 
animals breathe $5 \% \quad \mathrm{CO}_{2}$, in other words after 15 days $\mathrm{IH}$ animals hypoventilated in air and the three hypoxic atmospheres tested.

\section{DISCUSSION}

In the present work we have studied the effects of 8 and 15 days duration $\mathrm{IH}$ of moderate intensity as defined by nadir arterial $\mathrm{PO}_{2}(63.5 \pm 2.5 \mathrm{mmHg})$ on the entire arterial $\mathrm{CB}$ chemoreceptor arch, from chemoreceptor cells to ventilation, and have included a measurement of the utilization of CA by the sympathetic endings present in the renal artery. We have found that $\mathrm{IH}$ of 15 days duration produces marked changes in the levels and rate of CA synthesis in the CB chemoreceptor cells with a marked decrease in the content and normoxic rate of synthesis of NE and DA. Yet, turnover time for DA, the main CA in chemoreceptor cells, decreased by nearly $50 \%$ indicating a relative higher rate of DA utilization in normoxia in chemoreceptor cells. During acute hypoxic stimulation chemoreceptor cells of the CBS of $\mathrm{IH}$ animals responded with an exaggerated release of ${ }^{3} \mathrm{H}-\mathrm{CA}$ while the response elicited by a non-specific depolarizing stimulus (high external $\mathrm{K}^{+}$) was not significantly altered. The output of the CB measured at the level of the CSN, i.e., CB drive to brainstem, was diminished basally (normoxia) but exaggerated in response to hypoxia while response to high $\mathrm{PCO}_{2}$ /low pH remained nearly normal. Importantly enough, ventilatory responses were also altered in 15 days IH rats. They maintained BF in all experimental conditions $\left(20,12,10\right.$ and $7 \% \mathrm{O}_{2}$ and $5 \% \mathrm{CO}_{2}$ in air atmospheres) but exhibited a significantly lower TV, both factors made MV significantly lower in all conditions except in $\mathrm{CO}_{2}$ atmosphere. As a whole, data demonstrate that $\mathrm{IH}$ disrupts the normal relationship encountered between CSN activity and ventilation (Fidone and Gonzalez, 1986) with an increased in CSN firing induced by acute hypoxia in comparison to controls that was not followed by the expected exaggerated hyperventilatory response but instead $\mathrm{IH}$ animals hypoventilated in comparison to controls, implying profound changes in the brainstem integrating centers (Kline, 2010). Since these changes are accompanied by marked changes in the dynamics of NE in vascular sympathetic endings, our results indicate that $\mathrm{IH}$ causes that the input from the CB to the nucleus tractus solitarius (nTS) is integrated abnormally to generate 
an exaggerated output to the rostral ventrolateral medulla, a major source of excitation to the preganglionic sympathetic neurons in the intermediolateral column of the spinal cord (see below).

From Figure 1 it is evident that the rat CB is a catecholaminergic organ with DA being the dominant $\mathrm{CA}$ in relation to $\mathrm{NE}$ in a proportion of about 3:1. If we refer to chemoreceptor cells this ratio would increase to 10 or more, because most $(\approx 80)$ of the $N E$ content in the rat $C B$ is contained in the intraglomic sympathetic endings (Fidone and Gonzalez 1982, Mir et al., 1982). In the CBs of 15 days $\mathrm{IH}$ animals there is a marked decrease in the content of both CA to around $25-30 \%$ of control level, but the proportion between both CA is roughly maintained. The rate of ${ }^{3} \mathrm{HNE}$ and ${ }^{3} \mathrm{HDA}$ from their natural precursor ${ }^{3}$ HTyrosine (Figure 2) indicates that in the CBs of control animals the ratio of their rate of synthesis $\left({ }^{3} \mathrm{HDA} /{ }^{3} \mathrm{HNE}\right)$ is around 30-35 exceeding markedly the ratio of content and indicating that DA is used, and therefore renewed, much more rapidly than NE. In fact, the rate of ${ }^{3} \mathrm{HDA}$ and ${ }^{3} \mathrm{HNE}$ synthesis, $\approx 26$ pmole/mg of CB tissue/h and $\approx 0.85$ pmole $/ \mathrm{mg}$ of CB tissue $/ \mathrm{h}^{1}$, respectively, indicates that the $C B$ is using preferentially $D A$ as signalling molecule $a$, fact that we have emphasized previously (Fidone et al., 1992; Vicario et al., 2000; Conde et al., 2006). In the CBs from the 15 days $\mathrm{IH}$ animals rates of synthesis drop to around $10 \mathrm{pmole} / \mathrm{mg} \mathrm{CB} / \mathrm{h}$ for $\mathrm{DA}$ and $0.5 \mathrm{pmole} / \mathrm{mg} \mathrm{CB} / \mathrm{h}$ for $\mathrm{NE}$, evidencing that both CA, but particularly DA is used at much lower rate in $\mathrm{IH}$ organs. However the turnover times, i.e., content/rate of synthesis for DA in $\mathrm{IH}$ animals drops from 12 to $6.88 \mathrm{~h}$. Altogether data on CA content and rate of synthesis indicate that $\mathrm{IH}$ decreased drastically the normoxic storing capacity of the CB chemoreceptor cells for both CA, but reduced to a much lower extent their capacity to synthesize and use DA. These findings contrast with the well known effects of sustained hypoxia that increases both, the CA stores in chemoreceptor cells (Hanbauer et al., 1981; Pequignot et al., 1987) and the rate of CA synthesis (Caceres et al., 2007); these changes in CA metabolism in sustained hypoxia run in parallel to an increase in ventilation to hypoxia (acclimatization). In $\mathrm{IH}$, animals did not show acclimatization but they rather showed tolerance to the acute hypoxic response. Moreover, the effects

\footnotetext{
${ }^{1}$ This rate of synthesis does not correspond with turnover rates. It is an underestimate because the synthesis is not lineal for two hours (see Vicario et al., 2000).
} 
produced by $\mathrm{IH}$ appear to be rather specific of the hypoxic stimulation pattern and cannot be attributed to generalized alteration of the CA biosynthetic and storing machineries because in the sympathetic endings both the NE content and rate of synthesis is significantly increased (Figure 3; see below).

The overall shape of the time course of ${ }^{3} \mathrm{HCA}$ release (mostly ${ }^{3} \mathrm{HDA}$ release) experiments is very similar in the CBs of control and 15 days $\mathrm{IH}$ animals (Figures 4A and 4B). There are however important quantitative differences, being the most evident that the release of ${ }^{3} \mathrm{HCA}$ elicited by hypoxia is markedly increased (Figure $4 \mathrm{C}$ ). Once again the effects of $\mathrm{IH}$ contrast with those of sustained hypoxia (Gonzalez-Martin 2008) where a non specific an comparable sensitization leads to a parallel increase release in response to hypoxia and to high external $\mathrm{K}^{+}$which is probably due at least in part to an upregulation of L-type $\mathrm{Ca}^{2+}$ channels in the CB (Caceres et al., 2009). However, in the case of $\mathrm{IH}$ data would indicate that sensitization occurs in the transduction cascade upstream of cell depolarization (Gonzalez et al., 1992; Gonzalez et al., 2003). An upregulation of the $\mathrm{O}_{2}$-sensing mechanisms and/or $\mathrm{O}_{2}$-sensitive $\mathrm{K}^{+}$channels would satisfactorily explain findings. However, since CAMP stimulates the release of CA induced by hypoxia, and not the release induced by high $\mathrm{K}^{+}$(Perez-Garcia et al., 1991) by an EPAC mediated mechanism (Rocher et al., 2009) the upregulation of adenylyl cyclase of EPAC proteins can also account for the effects of $\mathrm{IH}$. Additionally, as suggested by Peng et al. (2003) the possibility exists that increased reactive oxygen species of mitochondrial origin, probably due to a downregulation of mitochondrial superoxide dismutase (Nanduri et al. 2009) or an induction of some isoform of NADPH oxidase (Peng et al., 2009; He et al., 2010) is responsible for chemoreceptor cell sensitization to hypoxia; yet the target of ROS remains to be defined. In any case, future experiments are required to disclose among these possibilities.

All considerations made to the release of ${ }^{3} \mathrm{HCA}$ induced by hypoxia in the CBs of $\mathrm{IH}$ animals are directly applicable to the activity in the CSN elicited by hypoxia. However we should make explicit that, even if during hypoxic stimulation in $\mathrm{IH}$ animals there is an increased DA concentration in the milieu surrounding the sensory nerve endings and a parallel increased level in neural discharge, we do not imply a cause effect relationship between both 
parameters. In all likelihood additional neurotransmitters co-released with DA (e.g., ATP that is co-stored with CA or acetylcholine; Nurse 2005), adenosine (Conde et al., 2009) or serotonin (Peng et al., 2009) are responsible for the augmentation of the hypoxic response. In sum, the genesis of the specific neural activity pattern, i.e., decreased basal activity, increased hypoxic activity and near normal hypercapnic response after 15 days of $\mathrm{IH}$, must imply profound changes in the storing capacity and dynamics of possibly several neurotransmitter systems (exemplified by CA) and/or changes in the density and/or affinity of their receptors.

The most unexpected finding was the marked decrease in ventilation in 15 days $\mathrm{IH}$ animals in all conditions except in hypercapnia. In a sense the maintenance of hypercapnic ventilation constitutes in itself an excellent intraexperimental control for potential uncontrolled spurious variables. Additionally, the fact that the data from 15 days $\mathrm{IH}$ animals were collected from two experimental batches of animals exposed to $\mathrm{IH}$ and studied several weeks apart and concurrently with animals exposed to 8 days of $\mathrm{IH}$ eliminate any methodological pitfall a give our findings a sound validation. The question emerges spontaneously: how is it possible that with a more intense CB input to the nTS, particularly to the commissural and medial subnuclei of the caudal nTS (Katz et al., 1997), it results a decreased ventilatory response in normoxia and hypoxia and maintenance of ventilation to high $\mathrm{CO}_{2}$ ? To provide a tentative answer to this question we should also consider that the particular ventilatory pattern generated by $\mathrm{IH}$ is associated to an increased sympathetic tone, as evidenced by many authors in their models of IH (e.g.; Zoccal et al., 2007; Xing and Pilowsky, 2010). Moreover, the present study also shows the increased levels and turnover rate of NE in sympathetic endings, which should result in an increase in circulating NE because no less than 75 of the circulating NE comes form sympathetic endings (Goldstein et al., 2003; see Gonzalez-Martín 2009). From a mechanistic point of view our findings can be interpreted as the result of abnormal integration in the nTS which would generate abnormal outputs with a deficient drive of the ventral respiratory column (that controls ventilation) and an exaggerated drive to the rostral ventrolateral medulla, a major source of excitation to the preganglionic sympathetic neurons in the intermediolateral column of the spinal cord normal coupling to respiration. Alternatively, the nTS 
can generate appropriate outputs, but postsynaptic mechanisms in the ventral respiratory column make it partially refractory to the CB chemoreceptor originated drive, while the opposite can happen in brainstem sympathetic neurons. A combination of both mechanisms can be operative as current literature describes both abnormal integration at nTS and exaggerated activation of sympathetic neurons in IH (Zoccal et al., 2009; Xing and Pilowsky, 2010; Kline 2010). The slight decrease of the ventilatory response to hypercapnia should be due to the fact that ventilation to hypercapnia is generated in only a small percentage $(\approx 30 \%)$ by the CB chemoreceptors being most of it generated at the central chemoreceptors located in the ventral medulla (Cherniak and Altose, 1997; Spyer and Gourine, 2009).

In sum, our study constitutes the first demonstration of the alteration of every element of the entire CB chemoreflex arch in $\mathrm{IH}$ animals demonstrating a sensitization of the afferent elements evidenced by exaggerated chemoreceptor cell and CSN responses to hypoxia and an alteration in the brainstem integration of the CB input leading to an altered function of the efferent arm of the reflex as evidenced by an exaggerated sympathetic neurotransmission and a reduced ventilation in normoxia and in response to hypoxia.

Acknowledgements. We want to thank $\mathrm{M}^{\mathrm{a}}$ de los Llanos Bravo and Elena Gonzalez for technical assistance. The work was supported Grants: BFU2007-61848 (DGICYT), CIBER CB06/06/0050 (FISS-ICiii), JCyL-GR242, SAF2007- 03948 and AGL2007-66108.

\section{REFERENCES}

1. Bao G, Metreveli N, Li R, Taylor A \& Fletcher EC (1997). Blood pressure response to chronic episodic hypoxia: role of the sympathetic nervous system. J Appl Physiol.83, 95-101.

2. Bisgard GE, Forster HV, Orr JA, Buss DD, Rawlings CA \& Rasmussen B (1976). Hypoventilation in ponies after carotid body denervation. J Appl Physiol. 40, 184-90. 
3. Bisgard GE (2000) .Carotid body mechanisms in acclimatization to hypoxia. Respir Physiol. 121, 237-46.

4. Caceres A I, Obeso A, Gonzalez C \& Rocher A (2007). Molecular identification and functional role of voltage-gated sodium channels in rat carotid body chemoreceptor cells. Regulation of expression by chronic hypoxia in vivo $\mathrm{J}$ Neurochem. 102, 231-45.

5. Cáceres Al, Gonzalez-Obeso E, Gonzalez C \& Rocher A (2009). RT-PCR and Pharmacological Analysis of L-and T-Type Calcium Channels in Rat Carotid Body. Adv Exp Med. Biol. 648, 105-112.

6. Cherniack N \& Altose M (1997). Central chemoreceptors. In: The Lung: Scientific Foundations. (Ed. Crystal, R., West, J., Weibel, E. \& Barnes, P). Lippincott - Raven. Philadelphia. pp.1767-1776.

7. Conde SV, Obeso A, Vicario I, Rigual R, Rocher A \& Gonzalez C (2006). Caffeine inhibition of rat carotid body chemoreceptors is mediated by $A_{2 A}$ and $A_{2 B}$ adenosine receptors. J Neurochem. 98, 616-28.

8. Conde SV, Obeso A \& Gonzalez C (2007). Low glucose effects on rat carotid body chemoreceptor cells secretory responses and action potential frequency in the carotid sinus nerve. J Physiol. 585, 721-30.

9. Conde SV, Monteiro EC, Obeso A \& Gonzalez C (2009). Adenosine in Peripheral Chemoreception: New Insights into a Historically Overlooked Molecule - Invited Article Adv Exp Med. Biol. 648, 145-160.

10. Costes F, Court-Fortune I, Fournel P, Vergnon JM, Emonot A \& Geyssant A (1995). Study of chemosensitivity in patients believed to have sleep apnea syndrome. Rev Mal Respir. 12, 359-64.

11. Fidone S \& Gonzalez C (1982). Catecholamine synthesis in rabbit carotid body in vitro. J Physiol. 333, 69-79.

12. Fidone S, Gonzalez C \& Yoshizaki K (1982). Effects of hypoxia on catecholamine synthesis in rabbit carotid body in vitro . J Physiol. 333, 81-91.

13. Fidone S, Gonzalez C \& Yoshizaki K (1982). Effects of low $\mathrm{O}_{2}$ on the release of dopamine from the rabbit carotid body in vitro. J Physiol. 333, 93-110.

14. Fidone S \& Gonzalez C (1986). Peripheral Chemoreceptors: Initiation and Control of Discharges. In: Handbook of Physiology. The Respiratory System II. (Ed. A.P. Fishman) Amer. Physiol. Soc. Bethesda, Maryland pp. 247-312. 
15. Fletcher EC, Lesske J, Behm R, Miller CC 3rd, Stauss H \& Unger T (1992). Carotid chemoreceptors, systemic blood pressure, and chronic episodic hypoxia mimicking sleep apnea. J Appl Physiol. 72, 1978-84.

16.García-Río F, Racionero MA, Pino JM, Martínez I, Ortuño F, Villasante C \& Villamor J (2000). Sleep apnea and hypertension. Chest. 117, 1417-25.

17.Goldstein DS, Eisenhofer G \& Kopin IJ (2003). Sources and significance of plasma levels of catechols and their metabolites in humans. J Pharmacol Exp Ther. 305, 800-11.

18. Gonzalez C, Almaraz L, Obeso A \& Rigual R (1992). Oxygen and acid chemoreception in the carotid body chemoreceptors. Trends Neurosci. 15:146153.

19.Gonzalez C, Almaraz L, Obeso A \& Rigual R (1994). Carotid Body Chemoreceptors: From Natural Stimuli to Sensory Discharges. Physiol. Rev. 74, 829-898.

20.Gonzalez C, Vaquero LM, López-López JR \& Pérez-García MT (2009).Oxygen-Sensitive Potassium Channels in Chemoreceptor Cells Physiology: Making a Virtue of Necessity. Ann. N Y Acad Sci 1177, 82-8.

21. Gonzalez C, Rocher A \& Zapata P (2003). Quimiorreceptores arteriales: mecanismos celulares y moleculares de las funciones adaptativa $y$ homeostática del cuerpo carotídeo. Rev. Neurol. 36, 239-254.

22. Gonzalez-Martin MC, Vega-Agapito V, Prieto-Lloret J, Agapito MT, Castañeda J \& Gonzalez C (2009). Effects of Intermittent Hypoxia on Blood Gases Plasma Catecholamine and Blood Pressure. Adv.Exp Med. Biol. 648, 319-328.

23. Greenberg HE, Sica A, Batson D \& Scharf SM (1999). Chronic intermittent hypoxia increases sympathetic responsiveness to hypoxia and hypercapnia. J Appl Physiol. 86, 298-305.

24. Hanbauer I, Karoum F, Hellstrom S \& Lahiri S (1981). Effects of hypoxia lasting up to one month on the catecholamine content in rat carotid body. Neurosc. 6:81-86.

25. He L, Liu X, Chen J, Dinger B, Stensaas L \& Fidone S (2010). Modulation of chronic hypoxia-induced chemoreceptor hypersensitivity by NADPH oxidase subunits in rat carotid body. J Appl Physiol. 108, 1304-1310. 
26. Hui AS, Striet JB, Gudelsky G, Soukhova GK, Gozal E, Beitner-Johnson D, Guo SZ, Sachleben LR Jr, Haycock JW, Gozal D \& Czyzyk-Krzeska MF (2003). Regulation of catecholamines by sustained and intermittent hypoxia in neuroendocrine cells and sympathetic neurons. Hypertension. 42,1130-6.

27. Katz DM, Finley JC , Erickson JT \& Brosenitsch T(1997). Organization and development of chemoafferent input to the brainstem. IN: C GonZALEZ (ED) The carotid Body Chemoreceptors. Springer, Heidelberg, PP 159-170.

28.Kemp PJ (2005). Hemeoxygenase-2 as an $\mathrm{O} 2$ sensor in $\mathrm{K}+$ channeldependent chemotransduction. Biochem Biophys Res Commun. 338, 648652.

29.Kimoff RJ, Brooks D, Horner RL, Kozar LF, Render-Teixeira CL, Champagne V, Mayer P \& Phillipson EA (1997). Ventilatory and arousal responses to hypoxia and hypercapnia in a canine model of obstructive sleep apnea. Am J Respir Crit Care Med. 156, 886-94.

30.Kline DD (2010). Chronic intermittent hypoxia affects integration of sensory input by neurons in the nucleus tractus solitarii. Respir Physiol Neurobiol. [Epub ahead of print]

31.Kumar GK, Rai V, Sharma SD, Ramakrishnan DP, Peng YJ, Souvannakitti D \& Prabhakar NR (2006). Chronic intermittent hypoxia induces hypoxiaevoked catecholamine efflux in adult rat adrenal medulla via oxidative stress. J Physiol. 575, 229-39.

32.Lesske J, Fletcher EC, Bao G \& Unger T (1997). Hypertension caused by chronic intermittent hypoxia--influence of chemoreceptors and sympathetic nervous system. J Hypertens. 15, 1593-603.

33.Leuenberger UA, Hogeman CS, Quraishi S, Linton-Frazier L, Gray KS (2007). Short-term intermittent hypoxia enhances sympathetic responses to continuous hypoxia in humans. J Appl Physiol. 103, 835-42.

34.Ling L, Fuller DD, Bach KB, Kinkead R, Olson EB Jr \& Mitchell GS (2001). Chronic intermittent hypoxia elicits serotonin-dependent plasticity in the central neural control of breathing. J Neurosci. 21, 5381-8.

35. Mir AK, McQueen DS, Pallot DJ \& Nahorski SR (1984). Direct biochemical and neuropharmacological identification of dopamine D2-receptors in the rabbit carotid body. Brain Res. 291, 273-83. 
36. Nanduri J, Wang N, Yuan G, Khan SA, Souvannakitti D, Peng YJ, Kumar GK, Garcia JA \& Prabhakar NR (2009). Intermittent hypoxia degrades HIF2alpha via calpains resulting in oxidative stress: implications for recurrent apnea-induced morbidities. Proc Natl Acad Sci U S A. 106, 1199-204.

37.Nurse CA (2005). Neurotransmission and neuromodulation in the chemosensory carotid body. Auton Neurosci. 120, 1-9.

38. Osanai S, Akiba Y, Fujiuchi S, Nakano H, Matsumoto H, Ohsaki Y \& Kikuchi K (1999). Depression of peripheral chemosensitivity by a dopaminergic mechanism in patients with obstructive sleep apnoea syndrome. Eur Respir J. 13, 418-23.

39.Peers C (1997). Oxygen-sensitive ion channels. Trends Pharmacol Sci . 18, 405-408.

40.Peng YJ, Overholt JL, Kline D, Kumar GK \& Prabhakar NR (2003). Induction of sensory long-term facilitation in the carotid body by intermittent hypoxia: implications for recurrent apneas. Proc Natl Acad Sci U S A. 100, 10073-8.

41.Peng YJ, Yuan G, Ramakrishnan D, Sharma SD, Bosch-Marce M, Kumar GK, Semenza GL \& Prabhakar NR (2006). Heterozygous HIF-1alpha deficiency impairs carotid body-mediated systemic responses and reactive oxygen species generation in mice exposed to intermittent hypoxia. $J$ Physiol. 577, 705-16.

42.Peng YJ, Nanduri J, Yuan G, Wang ., Deneris E, Pendyala S, Natarajan V, Kumar GK \& Prabhakar NR (2009). NADPH oxidase is required for the sensory plasticity of the carotid body by chronic intermittent hypoxia. $J$ Neurosci. 29, 4903-4910.

43. Pequignot JM, Cottet-Emard JM, Dalmaz Y, Peyrin L (1987). Dopamine and norepinephrine dynamics in rat carotid body during long-term hypoxia. $J$ Auton Nerv Syst 21, 9-14.

44.Perez-Garcia MT, Almaraz L \& Gonzalez C (1991). Differential modulation by cyclic AMP of catecholamine synthesis and release in the rabbit carotid body. J. Neurochem. 57, 1992-2000. 
45. Rocher A, Caceres AI, Almaraz L \& Gonzalez C (2009). EPAC signaling pathways are involved in low po2 chemoreception in carotid body chemoreceptor cells. J. Physiol. 587, 4015-27.

46.Sateia MJ (2003). Neuropsychological impairment and quality of life in obstructive sleep apnea. Clin Chest Med. 24, 249-59.

47.Schröder CM \& O'Hara R (2005). Depression and Obstructive Sleep Apnea (OSA). Ann Gen Psychiatry. 27, 4-13.

48.Spyer KM \& Gourine AV (2009). Chemosensory pathways in the brainstem controlling cardiorespiratory activity. Philos Trans $R$ Soc Lond B Biol Sci. 364, 2603-10.

49. Vicario I, Rigual R, Obeso A \& Gonzalez C (2000). Characterization of the synthesis and release of catecholamine in the rat carotid body in vitro. Am. J.Physiol. 278, C490-C499.

50.Weil JV (1986). Ventilatory control at high altitude. In: Handbook of Physiology, Section 3: The Respiratory System, Vol. II. Control of Breathing, Part 2, edited by A.P. Fishman, N.S. Cherniack, and J.G. Widdicombe. Bethesda, MD: American Physiological Society, p. 703-727.

51.Wilkinson KA, Huey KA, Dinger B, He L, Fidone SJ \&Powell FL Jr (2010). Chronic hypoxia increases the gain of the hypoxic ventilatory response by a mechanism in the central nervous system. J Appl Physiol. May 20. [Epub ahead of print]

52. Xing T, Pilowsky PM (2010). Acute intermittent hypoxia in rat in vivo elicits a robust increase in tonic sympathetic nerve activity that is independent of respiratory drive. J Physiol. Jun 21. [Epub ahead of print]

53.Zoccal DB, Bonagamba LG, Oliveira FR, Antunes-Rodrigues J \& Machado $\mathrm{BH}$ (2007). Increased sympathetic activity in rats submitted to chronic intermittent hypoxia. Exp Physiol. 92, 79-85.

54.Zoccal DB, Simms AE, Bonagamba LG, Braga VA, Pickering AE, Paton JF \& Machado $\mathrm{BH}$ (2008). Increased sympathetic outflow in juvenile rats submitted to chronic intermittent hypoxia correlates with enhanced expiratory activity. J Physiol. 586, 3253-65.

55.Zoccal DB, Paton JF \& Machado BH (2009). Do changes in the coupling between respiratory and sympathetic activities contribute to neurogenic hypertension?. Clin Exp Pharmacol Physiol. 36, 1188-96. 


\section{LEGENDS TO THE FIGURES}

Figure 1. Levels of catecholamines in the carotid bodies of control and 8 and 15 days intermittent hypoxic rats. Data are means \pm SEM of 24 (control) and 9 individual values ( 8 and 5 days $\mathrm{IH}$ ). ${ }^{\star *} \mathrm{p}<0.01$.

Figure 2. Rates of ${ }^{3} \mathrm{H}$-catecolamines synthesis from their natural precursor ${ }^{3} \mathrm{H}$-tyrosine by carotid bodies of control and 8 and 15 days intermittent hypoxic rats. Data are means \pm SEM of 24 (control) and 9 individual values (8 and 5 days $\mathrm{IH}) .{ }^{* *} \mathrm{p}<0.01$.

Figure 3. Endogenous norepinephrine levels and rates of ${ }^{3} \mathrm{H}$ norepinephrine synthesis from its natural precursor ${ }^{3} \mathrm{H}$-tyrosine in the renal artery of control and 8 and 15 days intermittent hypoxic rats. Data are means \pm SEM of 16 (control) and 9 individual values (8 and 5 days $\mathrm{IH}$ ). ${ }^{* *} \mathrm{p}<0.01$ and ${ }^{* * *} \mathrm{p}<0.001$.

Figure 4. Release of ${ }^{3} \mathrm{H}$-catecolamines by the carotid bodies of control and 8 and 15 days intermittent hypoxic rats. Effects of hypoxia and high external $\mathrm{K}^{+}$. A and B show, respectively, the mean time course of the release by the carotid bodies of control and 15 days $\mathrm{IH}$ rats. Empty bars, superfusion with $20 \% \mathrm{O}_{2}$-saturated solutions, dashed bars superfusion with hypoxic solution (7\% $\mathrm{O}_{2}$-saturated) and black columns superfusion with solutions $\left(20 \% \mathrm{O}_{2}\right.$ equilibrated) but containing $35 \mathrm{mM} \mathrm{K}^{+}$. The dotted line crossing the histograms separates the basal release (below the line) from the stimulus-induced release (above the line). C and D. Mean evoked release by hypoxia and high external $\mathrm{K}^{+}$, respectively. Data are means of 16 (control) and 8 individual values (8 and 15 days $\mathrm{IH}) .{ }^{* \star *} \mathrm{p}<0.001$.

Figure 5. Activity in paucifiber preparations of the carotid sinus nerve of control and 15 days ${ }^{* * *} p<0.001$. Effects of moderate and intense hypoxia and hypercapnia. A. Sample integrated response to moderate hypoxic stimulation of one control (black tracing) and one intermittent hypoxic animal (gray tracing). 
B. Mean basal normoxic (superfusion with $20 \% \quad \mathrm{O}_{2}$-equilibrated solutions) in control $(n=10)$ and 15 days intermittent hypoxic $(n=9)$ animals ${ }^{*} p<0.01$. C. Mean CSN responses in control and 15 days intermittent hypoxic animals to moderate and intense hypoxia and hypercapnia. Data (means $\pm S E M ; n=9$ ) are expressed as times basal: empty bars, control; black bars, intermittent hypoxic animals. ${ }^{* \star *} p<0.001$ D. Time required to reach maximal activity during stimulation. Data are means $\pm \mathrm{SEM}$; $n=9$ ). Empty bars, control; black bars, intermittent hypoxic animals. ${ }^{* \star} p<0.001$.

Figure 6. Normoxic, hypoxic and hypercapnic ventilation in control and 8 and 15 days intermittent hypoxic rats. A. Breathing frequency. B. Tidal volume by unit weight. C. Minute ventilation by unit weight. In all instances data are means \pm SEM of $16-20$ individual values for control animals, 8 individual values for 8 days and 12 individual values for 15 days intermittent hypoxic rats. ${ }^{\star} p<0.05 ;{ }^{* \star} p<0.01 ;{ }^{* \star} p<0.001$. 

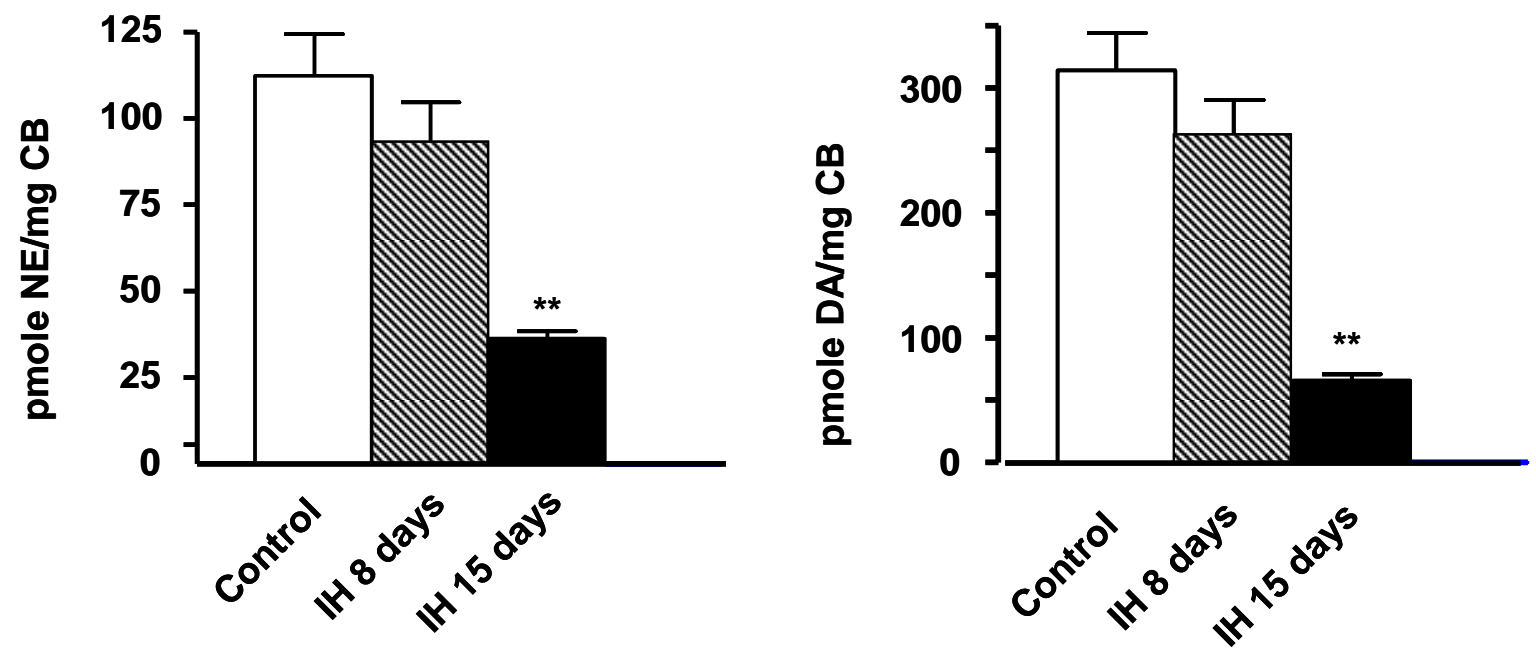

Gonzalez-Martin et al., Figure 1 

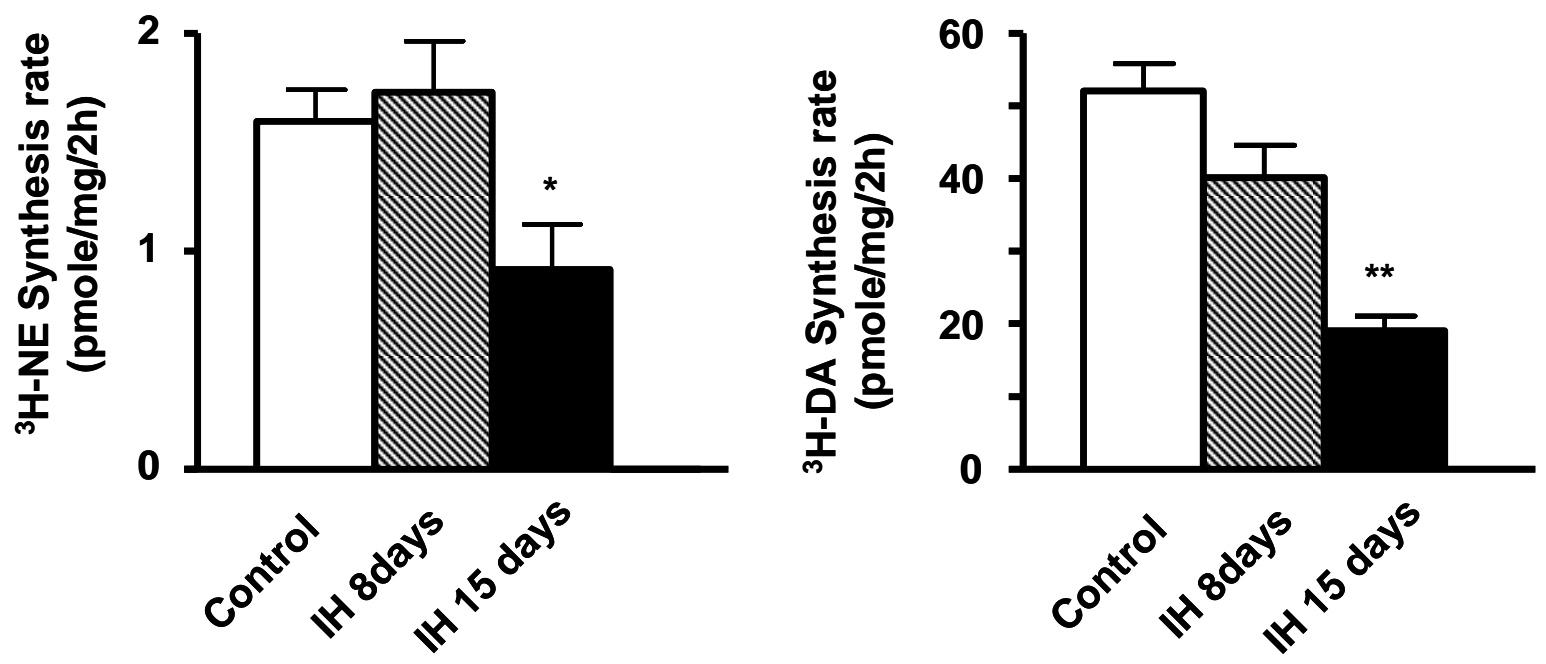

Gonzalez-Martin et al., Figure 2 

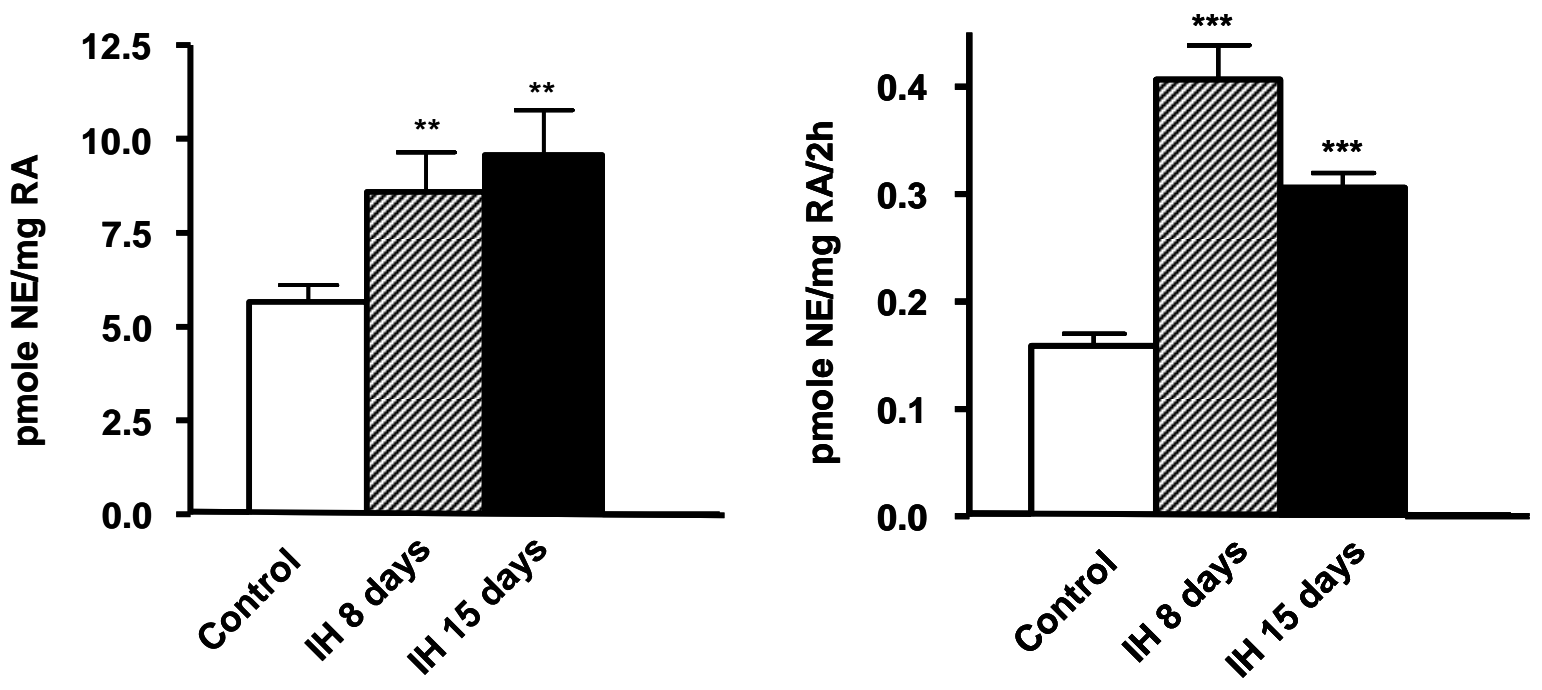

Gonzalez-Martin et al., Figure 3 

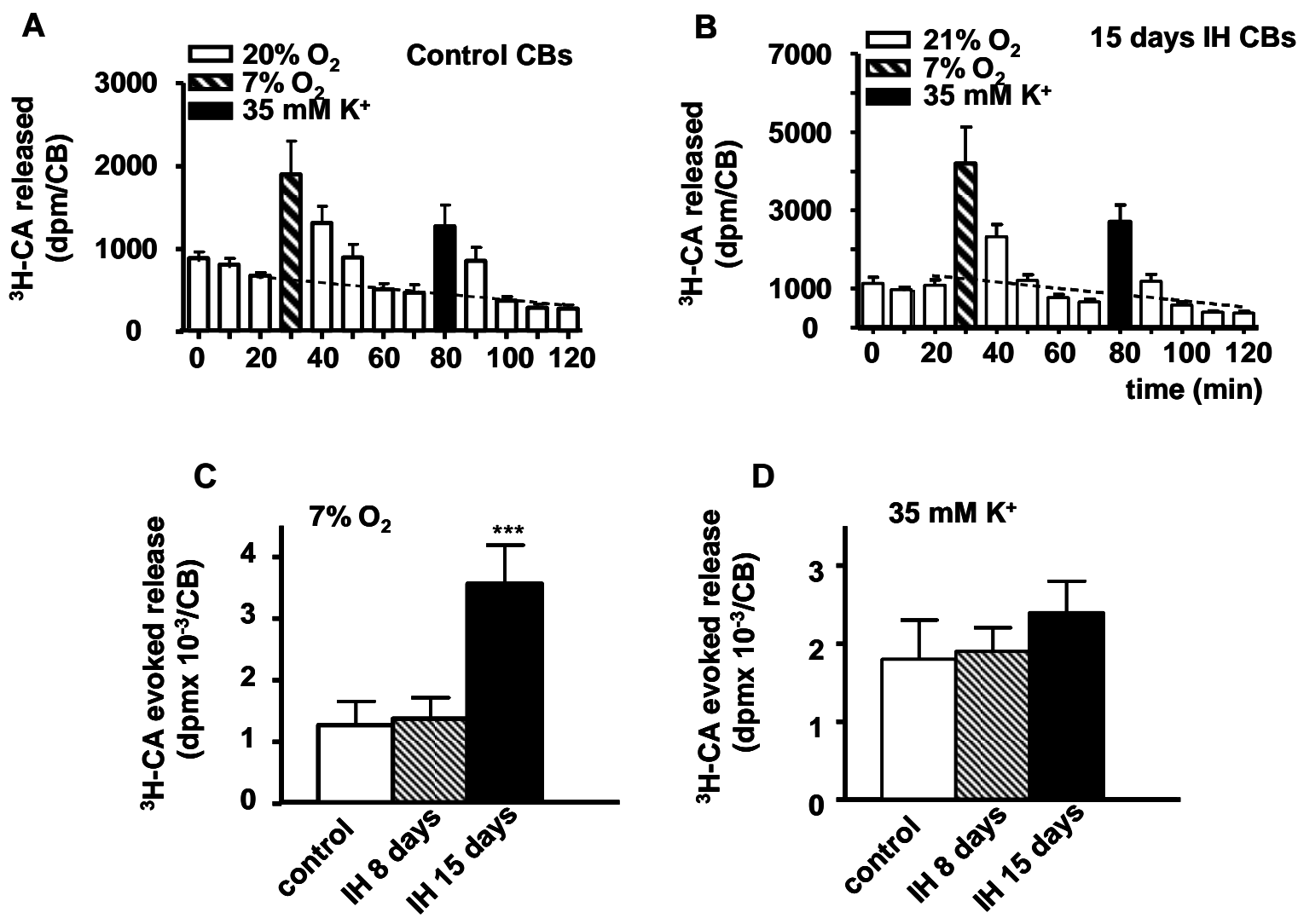

Gonzalez-Martin et al., Figure 4 
A
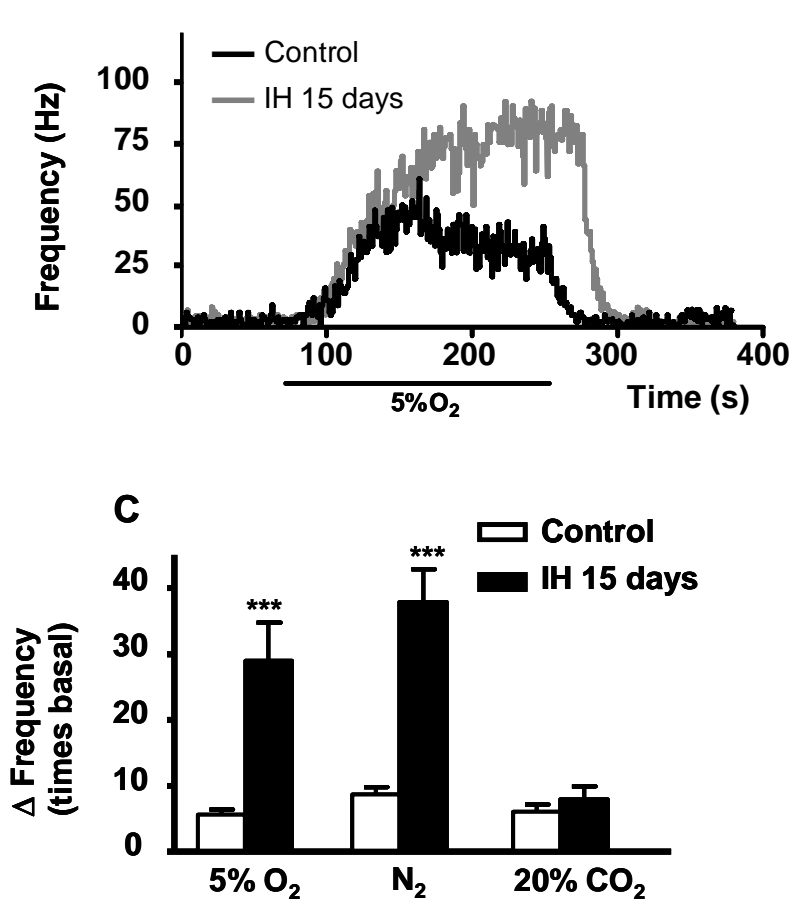

Gonzalez-Martin et al., Figure 5
B
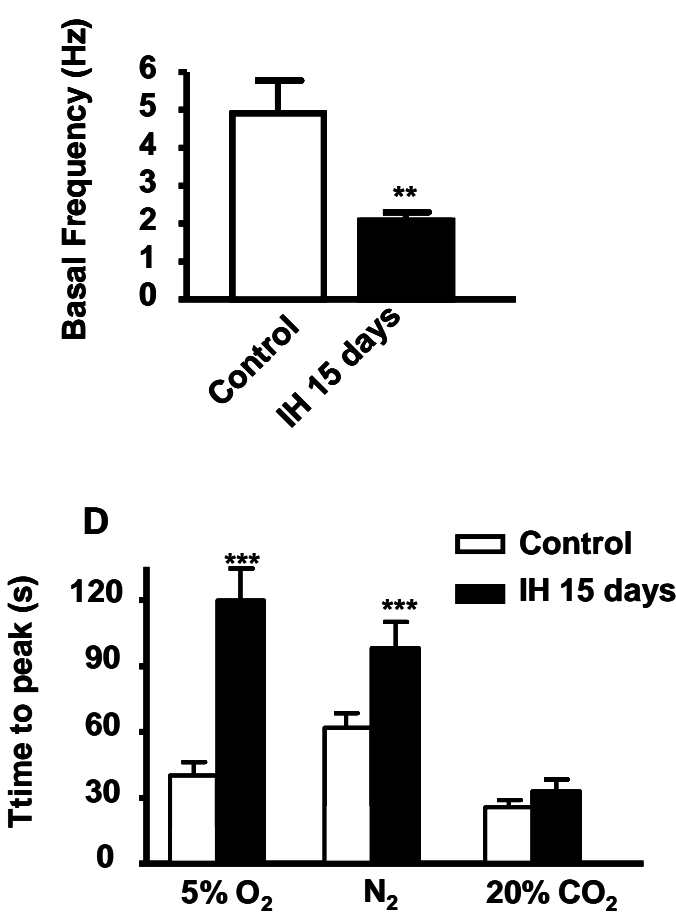

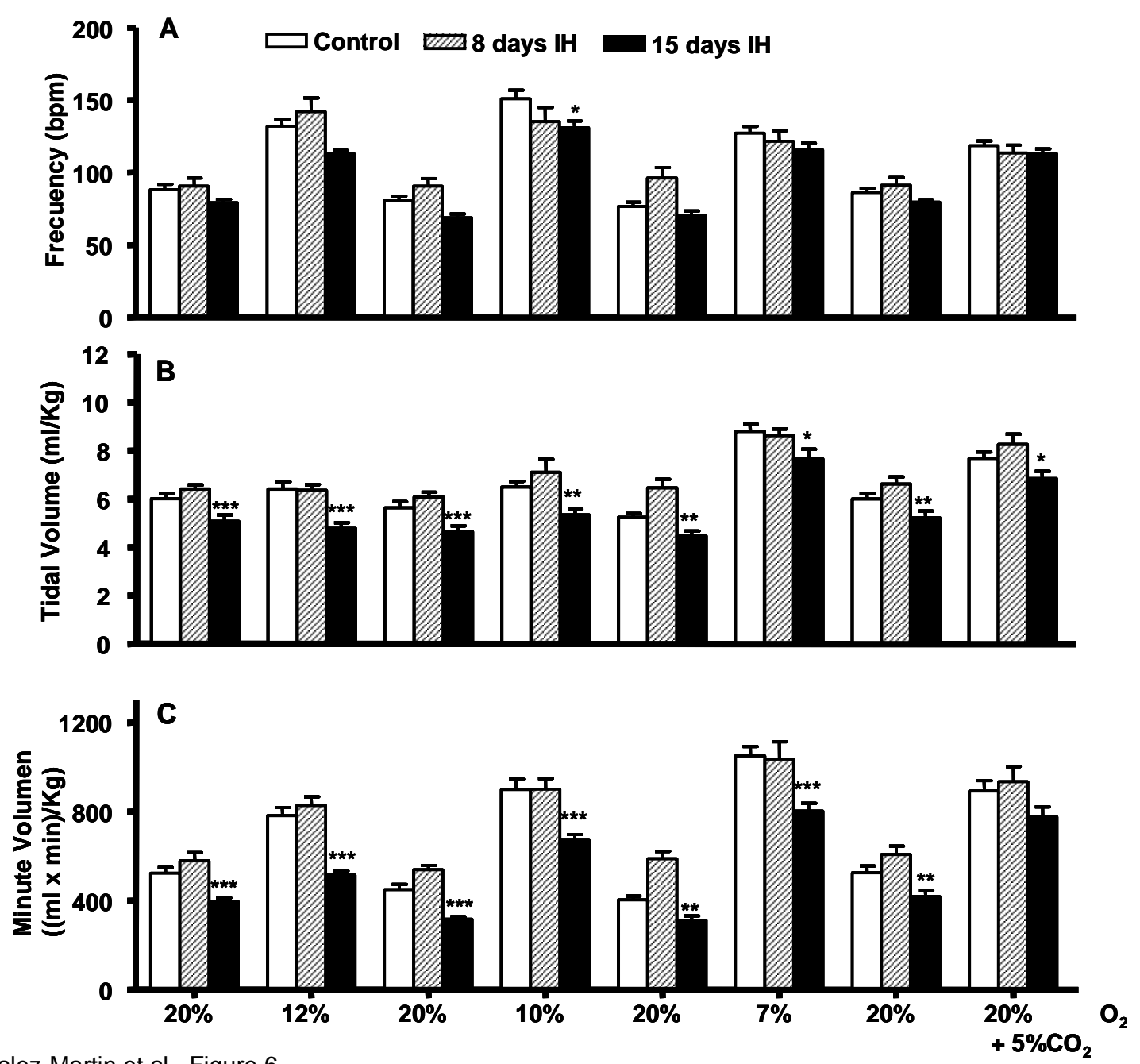

Gonzalez-Martin et al., Figure 6 